\title{
Point defects and mechanisms for the formation of thermoelectrical solid solutions $\mathrm{PbTe}_{\mathrm{Bi}} \mathrm{Te}_{3}$
}

\author{
Dmytro FREIK ${ }^{1 *}$, Liliya TUROVSKA ${ }^{1}$, Volodymyra BOYCHUK ${ }^{1}$ \\ ${ }^{1}$ Institute of Physics and Chemistry, Precarpathian National Vasyl Stefanyk University, \\ Shevchenka St. 57, 76018 Ivano-Frankivsk, Ukraine \\ * Corresponding author. Tel.: +380-34-2759214; fax:+380-34-2759214; e-mail: freik@pu.if.ua
}

Received December 7, 2011; accepted June 27, 2012; available on-line November 5, 2012

An analysis of the concentration and temperature dependencies of thermoelectrical parameters of the solid solutions $\mathrm{n}-\mathrm{PbTe}-\mathrm{Bi}_{2} \mathrm{Te}_{3}$ and $\mathrm{p}-\mathrm{PbTe}-\mathrm{Bi}_{2} \mathrm{Te}_{3}$ is presented. Two mechanisms for the formation of solid solutions based on PbTe have been considered within the framework of the crystal-quasi-chemical formalism: the substitution of bismuth ions at lead positions $\mathrm{Bi}_{\mathrm{Pb}}^{+}$with appearance of cation vacancies $\mathrm{V}_{\mathrm{Pb}}^{2-}$ (I) or neutral interstitial tellurium atoms $\mathrm{Te}_{\mathrm{i}}^{0}$ (II). The dependencies of the Hall concentration and the concentration of point defects on the composition of the solid solution and the initial deviation from stoichiometry in the matrix were calculated.

Lead telluride / Solid solution / Point defects / Crystal-quasi-chemical formulae / Mechanism for the formation of defects

\section{Точкові дефекти і механізми утворення термоелектричних твердих розчинів $\mathrm{PbTe}-\mathrm{Bi}_{2} \mathrm{Te}_{3}$}

\author{
Дмитро ФРЁ̈К ${ }^{1 *}$, Лілія ТУРОВСЬКАํ, Володимира БОЙчУК ${ }^{1}$ \\ ${ }^{1}$ Прикарпатський національний університет імені Василя Стефаника, \\ вул. Шевченка 57, 76018 м. Івано-Франківськ, Украӥна \\ * Контактна особа. Тел.: +380-34-2759214; факс:+380-34-2759214; e-mail: freik@pu.if.ua
}

Представлено аналіз концентраційних і температурних залежностей термоелектричних параметрів твердих розчинів n-PbTe-Bi ${ }_{2} \mathrm{Te}_{3}$ та p-PbTe-Bi ${ }_{2} \mathrm{Te}_{3}$. У рамках кристалоквазіхімічного формалізму розглянуто два механізми утворення твердих розчинів на основі РbТе: заміщення іонами бісмуту позицій плюмбуму $\mathrm{Bi}_{\mathrm{Pb}}^{+} 3$ появою катіонних вакансій $\mathrm{V}_{\mathrm{Pb}}^{2-}$ (I) чи нейтральних міжвузлових атомів телуру Те $_{i}^{0}$ (II). Розраховано залежності холлівської концентрації та концентрації точкових дефектів від складу твердого розчину і початкового відхилення від стехіометрії в матриці.

Плюмбум телурид / Твердий розчин / Точкові дефекти / Кристалоквазіхімічні формули / Механізм дефектоутворення

Вступ

Плюмбум телурид $\quad \epsilon \quad$ ефективним термоелектричним матеріалом в області середніх температур (500-750) $\mathrm{K}$, а $\mathrm{Bi}_{2} \mathrm{Te}_{3}$ - кімнатних $(300$ K) [1-4]. Перспективність твердих розчинів

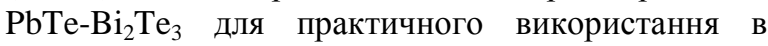
термоелектриці визначається різким зниженням граткової теплопровідності, яке зумовлено наявністю в складі сполук важких атомів, а також значним ступенем розупорядкування кристалічної гратки за рахунок високої концентрації точкових дефектів. Відомо [1], що термоелектрична добротність (Z) матеріалу визначається коефіцієнтом термо-е.p.c. $(\alpha), \quad$ питомою електропровідністю $(\sigma)$ та сумою електронної $\left(\chi_{\mathrm{e}}\right)$ 
та граткової $\left(\chi_{\mathrm{r}}\right)$ складових теплопровідності $\left(\chi=\chi_{\mathrm{e}}+\chi_{\mathrm{r}}\right)$ через співвідношення $\mathrm{Z}=\alpha^{2} \sigma / \chi$. Зрозуміло, що велике значення $\mathrm{Z}$, за яким визначається комерційне використання термоелектричного матеріалу, залежить від $\alpha$ i $\sigma$, які $є$ чутливими до природи електронних станів. При цьому зменшення складових теплопровідності, які визначаються фононним спектром кристалу $\left(\chi_{\mathrm{r}}\right)$ і концентрацією носіїв заряду $\left(\chi_{\mathrm{e}}\right)$, є одним із ефективних напрямків підвищення значення термоелектричної добротності. Зауважимо, що як електронна, так i фононна підсистеми кристалу суттєво залежать від його дефектного стану: власних і домішкових точкових дефектів та їхніх комплексів. У зв'язку із цим йде пошук нових сполук зі складними кристалічними структурами, для яких характерна низька теплопровідність. Серед них відзначаються квазібінарні системи типу $\mathrm{A}^{\mathrm{IV}} \mathrm{B}^{\mathrm{VI}}-\mathrm{C}_{2}^{\mathrm{V}} \mathrm{B}_{3}^{\mathrm{VI}}\left(\mathrm{A}^{\mathrm{IV}}-\right.$ $\left.\mathrm{Ge}, \mathrm{Sn}, \mathrm{Pb} ; \mathrm{C}^{\mathrm{V}}-\mathrm{Bi}, \mathrm{Sb} ; \mathrm{B}^{\mathrm{VI}}-\mathrm{Te}\right)$ і особливо - тверді

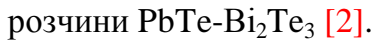

У цій роботі в рамках кристалохімічного формалізму зроблено детальний аналіз можливих механізмів утворення твердих розчинів $\mathrm{PbTe}-$ $\mathrm{Bi}_{2} \mathrm{Te}_{3}$, визначено їхній вплив на дефектну підсистему та концентрацію як окремих точкових дефектів, так і носіїв струму.

\section{Фізико-хімічні властивості}

Розчинність $\mathrm{Bi}_{2} \mathrm{Te}_{3}$ в РbTе становить за даними різних авторів 5-10 мол. \% [5-10]. На Рис. 1 показана залежність термоелектричних параметрів для n-PbTe-Bi $\mathrm{Te}_{3}$ від вмісту $\mathrm{Bi}_{2} \mathrm{Te}_{3}$ [11]. Питомий електричний опір (Рис. 1 - крива 1) спадає, а концентрація носіїв (Рис. 1 - крива 2) твердого розчину зростає зі збільшенням вмісту $\mathrm{Bi}_{2} \mathrm{Te}_{3}$. Холлівська рухливість має максимум при 0,3 мол. \% $\mathrm{Bi}_{2} \mathrm{Te}_{3}$ (Рис. 1 - крива 3). Аналізуючи значення коефіцієнта термо-е.р.с. (Рис. 1 крива 4) в залежності від складу, можна побачити, що всі зразки мають n-тип провідності. Коефіцієнт термо-е.p.c. за абсолютною величиною підтримується майже постійним при вмісті $\mathrm{Bi}_{2} \mathrm{Te}_{3}$ менше 0,3 мол. \% i має різкий максимум для 0,3 мол. \% $\mathrm{Bi}_{2} \mathrm{Te}_{3}$ (Рис. 1 - крива 4). При цьому загальна теплопровідність $\chi$ зберігається майже постійною $\left(\chi=2,3 \mathrm{BTK}^{-1} \mathrm{M}^{-1}\right)$ і $є$ набагато меншою, ніж у $\mathrm{PbTe}$, легованого іншими домішками [11]. 3i збільшенням частки $\mathrm{Bi}_{2} \mathrm{Te}_{3}$ граткова теплопровідність $\chi_{\mathrm{r}}$ лінійно зменшується, а електронна $\chi_{\mathrm{e}}$ - лінійно зростає [11]. Термоелектрична добротність Z (Рис. 1 - крива 5) твердого розчину n-PbTe- $\mathrm{Bi}_{2} \mathrm{Te}_{3}$ спочатку різко збільшується, а потім зменшується зі збільшенням вмісту $\mathrm{Bi}_{2} \mathrm{Te}_{3}$ i має чітко виражений максимум при 0,3 мол. \% $\mathrm{Bi}_{2} \mathrm{Te}_{3}$, який при кімнатній температурі становить $7,63 \cdot 10^{-4} \mathrm{~K}^{-1}$. Ці значення у кілька разів більші, ніж значення для зразків $\mathrm{PbTe}$, легованих $\mathrm{PbI}_{2}[12,13]$.

Для сплаву $\mathrm{p}-\mathrm{PbTe}_{\mathrm{B}} \mathrm{Bi}_{2} \mathrm{Te}_{3}$ [14] коефіціснт термо-е.p.c., змінивши знак при $\sim 0,1$ мол. \% $\mathrm{Bi}_{2} \mathrm{Te}_{3}$, зростає по абсолютній величині і при $\sim 0,5$ мол. \% $\mathrm{Bi}_{2} \mathrm{Te}_{3}$ досягає максимуму, потім зменшується до величини 45 мкВ/К при (2-3) мол. \% $\mathrm{Bi}_{2} \mathrm{Te}_{3}$, після чого практично не змінюється (Рис. 2 - крива 1). Характер залежності $\alpha$ від складу і значення коефіцієнта термо-е.p.c. досить добре узгоджуються 3 даними робіт [6-10]. При збільшенні вмісту $\mathrm{Bi}_{2} \mathrm{Te}_{3}$ до 3 мол. \% спостерігається зростання концентрації носіїв струму, після чого вона практично не змінюється (Рис. 2 - крива 2). На залежності мікротвердості від складу відзначається зростання $\mathrm{H}$ зі збільшенням вмісту $\mathrm{Bi}_{2} \mathrm{Te}_{3}$ в $\mathrm{PbTe}$ за рахунок блокування руху дислокацій атомами домішки (Рис. 2 - крива 3). При концентраціях домішки більше 5 мол. $\% \quad \mathrm{Bi}_{2} \mathrm{Te}_{3}$ мікротвердість не

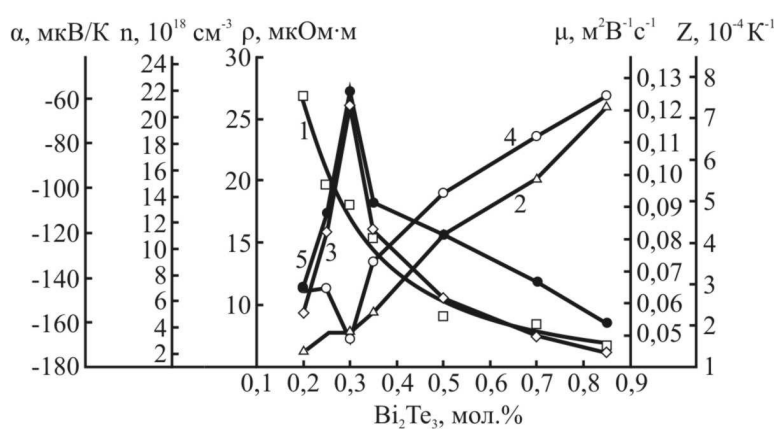

Рис. 1. Залежність термоелектричних параметрів твердих розчинів n-PbTe- $\mathrm{Bi}_{2} \mathrm{Te}_{3}$ від вмісту $\mathrm{Bi}_{2} \mathrm{Te}_{3}$ : 1 - питомий опір $\rho ; 2$ - концентрація носіїв $\mathrm{n}$; 3 - холлівська рухливість $\mu ; 4$ - коефіцієнт термоe.p.c. $\alpha ; 5$ - термоелектрична добротність Z [11].

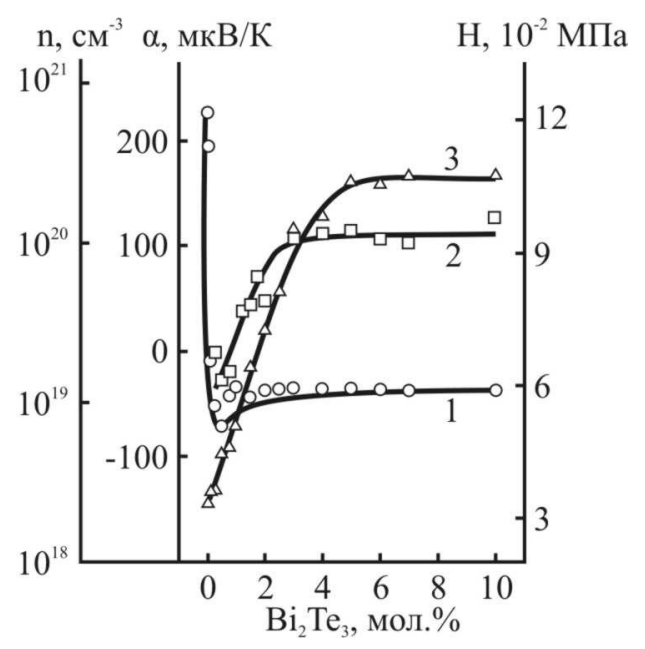

Рис. 2. Залежність термоелектричних параметрів твердих розчинів p-PbTe- $\mathrm{Bi}_{2} \mathrm{Te}_{3}$ від вмісту $\mathrm{Bi}_{2} \mathrm{Te}_{3}$ : 1 - коефіціснт термое.p.c. $\alpha ; 2-$ концентрація носіїв $\mathrm{n}$; 3 - мікротвердість Н [14]. 
змінюється від складу, що свідчить про досягнення межі області розчинності і добре узгоджується з даними роботи [7].

\section{Кристалоквазіхімічні формули}

В основі кристалоквазіхімічного підходу лежить поняття антиструктури [15], яка для плюмбум телуриду має вигляд $\mathrm{V}_{\mathrm{Pb}}^{\prime \prime} \mathrm{V}_{\mathrm{Te}}^{\bullet \bullet}$, де $\mathrm{V}_{\mathrm{Pb}}^{\prime \prime}$ i $\mathrm{V}_{\mathrm{Te}}^{\bullet \bullet}$ двозарядні вакансії плюмбуму i телуру, відповідно; “”” і “॰” - негативний і позитивний заряди, відповідно. Кристалоквазіхімічна формула твердого розчину записується як суперпозиція легуючого кластера, утвореного на основі антиструктури основної матриці, i формули базової сполуки.

Розглянемо два можливих механізми утворення твердого розчину $\mathrm{PbTe}_{-} \mathrm{Bi}_{2} \mathrm{Te}_{3}$ : заміщення іонами бісмуту позицій плюмбуму 3 утворенням катіонних вакансій (механізм I) та заміщення $\mathrm{Bi}$ позицій $\mathrm{Pb} 3$ утворенням міжвузлового телуру (механізм II).

Механізм I. 3 розрахунку на 1 атом телуру та 3 врахуванням зарядового стану іонів формула для легуючого компоненту матиме вигляд: $\mathrm{Bi}_{2}^{3+} \mathrm{Te}^{2-}$. Легуючий кластер в такому вивадку запишеться як:

$\mathrm{V}_{\mathrm{Pb}}^{\prime /} \mathrm{V}_{\mathrm{Te}}^{\bullet \bullet}+\mathrm{Bi}_{\frac{2}{3}}^{\bullet \bullet \bullet} \mathrm{Te}^{\prime /} \rightarrow\left[\mathrm{Bi}_{\frac{2}{3}}^{\bullet} \mathrm{V}_{\frac{1}{3}}^{\prime /}\right]_{\mathrm{Pb}} \mathrm{Te}_{\mathrm{Te}}^{\times}$,

де “ $x "$ - нейтральний заряд.

Тоді кристалоквазіхімічна формула n-PbTe$\mathrm{Bi}_{2} \mathrm{Te}_{3}$ як суперпозиція легуючого кластера (1) 3 кристалоквазіхімічною формулою n-PbTe [16]:

$$
\begin{aligned}
& (1-\mathrm{x})\left\{\begin{array}{l}
{\left[\mathrm{Pb}_{1-\alpha \sigma}^{\mathrm{x}} \mathrm{V}_{\alpha \sigma(1-\delta)}^{\prime \prime} \mathrm{V}_{\alpha \sigma \delta}^{\prime}\right]_{\mathrm{Pb}}\left[\mathrm{Te}_{1-\alpha}^{\mathrm{x}} \mathrm{V}_{\alpha}^{\bullet \bullet \bullet}\right]_{\mathrm{Te}} \times} \\
\times\left(\mathrm{Pb}_{\alpha \sigma}^{\bullet \bullet \bullet}\right)_{\mathrm{i}}+(2 \alpha+\alpha \sigma \delta) \mathrm{e}^{-}
\end{array}\right\} \\
& +\mathrm{x}\left\{\left[\begin{array}{r}
\left.\left.\mathrm{Bi}_{\frac{2}{3}}^{\bullet} \mathrm{V}_{\frac{1}{3}}^{\prime \prime}\right]_{\mathrm{Pb}} \mathrm{Te}_{\mathrm{Te}}^{\mathrm{x}}\right\} \rightarrow \\
\rightarrow\left[\mathrm{Pb}_{(1-\mathrm{x})(1-\alpha \sigma)}^{\mathrm{x}} \mathrm{Bi}_{\frac{2}{3}} \mathrm{x} \quad \mathrm{V}_{\alpha \sigma(1-\delta)(1-\mathrm{x})+\frac{1}{3} \mathrm{x}}^{\prime \prime} \mathrm{V}_{\alpha \sigma \delta(1-\mathrm{x})}^{\prime}\right.
\end{array}\right]\right. \\
& \times{ }_{\mathrm{Pb}}\left[\mathrm{Te}_{(1-\alpha)(1-\mathrm{x})+\mathrm{x}}^{\mathrm{x}} \mathrm{V}_{\alpha(1-\mathrm{x})}^{\bullet \bullet}\right]_{\mathrm{Te}}\left(\mathrm{Pb}_{\alpha \sigma(1-\mathrm{x})}^{\bullet \bullet}\right)_{\mathrm{i}} \\
& +(2 \alpha+\alpha \sigma \delta)(1-\mathrm{x}) \mathrm{e}^{-} .
\end{aligned}
$$

Тут $\mathrm{x}-$ мольна частка $\mathrm{Bi}_{2} \mathrm{Te}_{3}, \alpha-$ величина початкового відхилення від стехіометрії зі сторони $\mathrm{Pb}, \quad \delta-\quad$ коефіцієнт диспропорціонування зарядового стану вакансій плюмбуму, $\sigma$ - частка міжвузлового плюмбуму $\mathrm{Pb}_{\mathrm{i}}, \mathrm{e}^{-}$- електрон.

Аналогічним чином у випадку $\mathrm{p}-\mathrm{PbTe}-\mathrm{Bi}_{2} \mathrm{Te}_{3}$ :

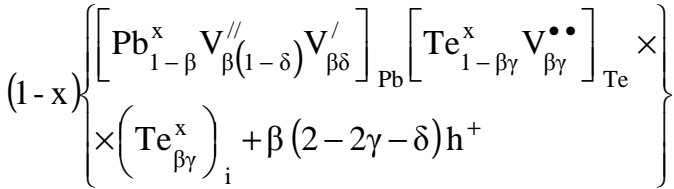

$$
\begin{aligned}
& +\mathrm{X}\left\{\left[\begin{array}{cc}
\mathrm{Bi}_{2}^{\bullet} \mathrm{V}_{\frac{1}{3}}^{\prime \prime} & \frac{1}{3}
\end{array}\right]_{\mathrm{Pb}} \mathrm{Te}_{\mathrm{Te}}^{x}\right\} \rightarrow
\end{aligned}
$$

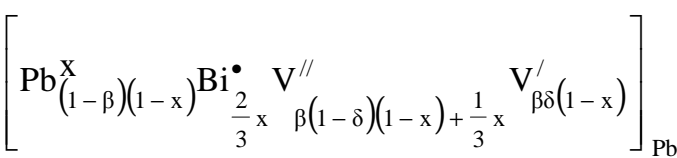

$$
\begin{aligned}
& \left.\times\left[\operatorname{Te}_{(1-\beta \gamma}^{\mathrm{x}}\right)(1-\mathrm{x})+\mathrm{x} \mathrm{V}_{\beta \gamma(1-\mathrm{x})}^{\bullet \bullet}\right]_{\mathrm{Te}}\left(\operatorname{Te}_{\beta \gamma(1-\mathrm{x})}^{\mathrm{x}}\right)_{\mathrm{i}}+ \\
& +\beta(2-2 \gamma-\delta)(1-\mathrm{x}) \mathrm{h}^{+} \text {. }
\end{aligned}
$$

Тут $\beta$ - величина початкового відхилення від стехіометрії зі сторони Те, $\gamma$ - частка міжвузлового телуру $\mathrm{Te}_{\mathrm{i}}, \mathrm{h}^{+}$- дірка.

Механізм II. 3 розрахунку на 1 атом бісмуту та 3 врахуванням зарядового стану іонів формула для легуючого компоненту матиме вигляд: $\mathrm{Bi}^{3+} \mathrm{Te}_{\frac{3}{2}}^{2-}$. Легуючий кластер:

$\mathrm{V}_{\mathrm{Pb}}^{/ /} \mathrm{V}_{\mathrm{Te}}^{\bullet \bullet}+\mathrm{Bi}^{\bullet \cdots \bullet} \mathrm{Te}_{\frac{3}{2}}^{/ /} \rightarrow \mathrm{Bi}_{\mathrm{Pb}}^{\bullet} \mathrm{Te}_{\mathrm{Te}}^{\mathrm{x}}\left(\mathrm{Te}_{\frac{1}{2}}^{\mathrm{x}}\right)_{\mathrm{i}}+\mathrm{e}^{-}$

Тоді кристалоквазіхімічна формула n-PbTe$\mathrm{Bi}_{2} \mathrm{Te}_{3}$ :

$$
\begin{aligned}
& (1-\mathrm{x})\left\{\begin{array}{l}
{\left[\mathrm{Pb}_{1-\alpha \sigma}^{\times} \mathrm{V}_{\alpha \sigma(1-\delta)}^{\prime \prime} \mathrm{V}_{\alpha \sigma \delta}^{\prime}\right]_{\mathrm{Pb}} \times} \\
{\left[\mathrm{Te}_{1-\alpha}^{\times} \mathrm{V}_{\alpha}^{\bullet \bullet}\right]_{\mathrm{Te}}\left(\mathrm{Pb}_{\alpha \sigma}^{\bullet \bullet}\right)_{\mathrm{i}}+(2 \alpha+\alpha \sigma \delta) \mathrm{e}^{-}}
\end{array}\right\}+ \\
& \mathrm{x}\left\{\mathrm{Bi}_{\mathrm{Pb}}^{\bullet} \mathrm{Te}_{\mathrm{Te}}^{\times}\left(\mathrm{Te}_{\frac{1}{2}}^{\times}\right)_{\mathrm{i}}+\mathrm{e}^{-}\right\} \rightarrow \\
& \rightarrow\left[\mathrm{Pb}_{(1-\mathrm{x})(1-\alpha \sigma)}^{\times} \mathrm{Bi}_{\mathrm{x}}^{\bullet} \mathrm{V}_{\alpha \sigma(1-\delta)(1-\mathrm{x})}^{\prime \prime} \mathrm{V}_{\alpha \sigma \delta(1-\mathrm{x})}^{\prime}\right]_{\mathrm{Pb}} \times \\
& {\left[\mathrm{Te}_{(1-\alpha)(1-\mathrm{x})+\mathrm{x}}^{\times} \mathrm{V}_{\alpha(1-\mathrm{x})}^{\bullet \bullet}\right]_{\mathrm{Te}}\left(\mathrm{Pb}_{\alpha \sigma(1-\mathrm{x})}^{\bullet \bullet \bullet}\right)_{\mathrm{i}} \times} \\
& \left(\operatorname{Te}_{\frac{1}{2} \mathrm{x}}^{\times}\right)_{\mathrm{i}}+\{(2 \alpha+\alpha \sigma \delta)(1-\mathrm{x})+\mathrm{x}\} \mathrm{e}^{-},
\end{aligned}
$$

a p-PbTe- $\mathrm{Bi}_{2} \mathrm{Te}_{3}$ :

$$
\begin{aligned}
& (1-\mathrm{x})\left\{\begin{array}{l}
{\left[\begin{array}{ll}
\mathrm{Pb}_{1-\beta}^{\times} \mathrm{V}_{\beta(1-\delta)}^{\prime \prime} & \mathrm{V}_{\beta \delta}^{\prime}
\end{array}\right]_{\mathrm{Pb}}\left[\mathrm{Te}_{1-\beta \gamma}^{\times} \mathrm{V}_{\beta \gamma}^{\bullet \bullet}\right]_{\mathrm{Te}} \times} \\
\left(\mathrm{Te}_{\beta \gamma}^{\times}\right)_{\mathrm{i}}+\beta(2-2 \gamma-\delta) \mathrm{h}^{+}
\end{array}\right\}+ \\
& \mathrm{x}\left\{\mathrm{Bi}_{\mathrm{Pb}}^{\bullet} \mathrm{Te}_{\mathrm{Te}}^{\times}\left(\mathrm{Te}_{\frac{1}{2}}^{\times}\right)_{\mathrm{i}}+\mathrm{e}^{-}\right\} \rightarrow
\end{aligned}
$$


$\rightarrow\left[\mathrm{Pb}_{(1-\beta)(1-\mathrm{x})}^{\times} \mathrm{Bi}_{\mathrm{x}}^{\bullet} \mathrm{V}_{\beta(1-\delta)(1-\mathrm{x})}^{\prime \prime} \mathrm{V}_{\beta \delta(1-\mathrm{x})}^{\prime}\right]_{\mathrm{Pb}} \times$

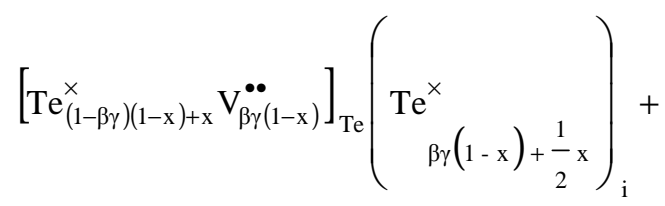

$\beta(2-2 \gamma-\delta)(1-\mathrm{x}) \mathrm{h}^{+}+\mathrm{xe}^{-}$

Запропоновані механізми легування, а також кристалоквазіхімічні формули (2)-(6) дають можливість знайти аналітичні залежності як концентрації окремих точкових дефектів, так i носіїв струму від величини відхилення від стехіометричного складу у базовій сполуці $(\alpha, \beta)$ i складу твердого розчину (х). Так, зокрема, для $\mathrm{n}-\mathrm{PbTe}-\mathrm{Bi}_{2} \mathrm{Te}_{3}$ (механізм I), згідно 3 кристалоквазіхімічною формулою (2), повне рівняння електронейтральності запишеться таким чином:

$\mathrm{n}+\left|\mathrm{q}_{\mathrm{V}_{\mathrm{Pb}}^{\prime \prime}}\right|\left[\mathrm{V}_{\mathrm{Pb}}^{\prime /}\right]+\left|\mathrm{q}_{\mathrm{V}_{\mathrm{Pb}}^{\prime}}\right|\left[\mathrm{V}_{\mathrm{Pb}}^{\prime}\right]=$

$=\left|\mathrm{q}_{\mathrm{V}_{\mathrm{Te}}}\right|\left[\mathrm{V}_{\mathrm{Te}}^{\bullet \bullet}\right]+\left|\mathrm{q}_{\mathrm{Pb}_{\mathrm{i}}} \cdot\right|\left[\mathrm{Pb}_{\mathrm{i}}^{\bullet \bullet}\right]+\left|\mathrm{q}_{\mathrm{Bi}_{\mathrm{Pb}}}\right|\left[\mathrm{Bi}_{\mathrm{Pb}}^{\bullet}\right]$,

де $\mathrm{n}=\mathrm{A}(2 \alpha+\alpha \sigma \delta)(1-\mathrm{x})$,

$\left[\mathrm{V}_{\mathrm{Pb}}^{\prime \prime}\right]=\mathrm{A}\left(\alpha \sigma(1-\delta)(1-\mathrm{x})+\frac{1}{3} \mathrm{x}\right),\left\lfloor\mathrm{V}_{\mathrm{Pb}}^{\prime}\right\rfloor=\mathrm{A} \alpha \alpha \sigma(1-\mathrm{x})$,

$\left[\mathrm{Bi}_{\mathrm{Pb}}^{\bullet}\right]=\frac{2}{3} \mathrm{Ax},\left|\mathrm{V}_{\mathrm{Te}}^{\bullet \bullet}\right|=\mathrm{A} \alpha(1-\mathrm{x}),\left|\mathrm{Pb}_{\mathrm{i}}^{\bullet \bullet}\right|=\mathrm{A} \alpha \sigma(1-\mathrm{x})$,

$\left|\mathrm{q}_{\mathrm{V}_{\mathrm{Pb}}^{\prime}}\right|=\left|\mathrm{q}_{\mathrm{Bi}_{\mathrm{Pb}}}\right|=1,\left|\mathrm{q}_{\mathrm{V}_{\mathrm{Pb}}^{\prime \prime}}\right|=\left|\mathrm{q}_{\mathrm{V}_{\mathrm{Te}} \cdot}\right|=\left|\mathrm{q}_{\mathrm{Pb}_{3}}\right|=2$,

$\mathrm{A}=\frac{2 \mathrm{Z}}{a^{3}}, \mathrm{Z}-$ кількість структурних одиниць в елементарній комірці $(\mathrm{Z}=4), a$ - параметр гратки $(a=6.439 \AA)$.

Холлівська концентрація носіїв струму $\mathrm{n}_{\mathrm{H}}$ в цьому випадку буде визначатися як:

$\mathrm{n}_{\mathrm{H}}=\mathrm{A}(2 \alpha+\alpha \gamma \delta)(1-\mathrm{x})$.

Аналогічно для p-PbTe-Bi $\mathrm{Te}_{3}$ (механізм I), згідно з (3), рівняння електронейтральності:

$\left|\mathrm{q}_{\mathrm{V}_{\mathrm{Pb}}^{\prime \prime}}\right|\left[\mathrm{V}_{\mathrm{Pb}}^{\prime \prime}\right]+\left|\mathrm{q}_{\mathrm{V}_{\mathrm{Pb}}^{\prime}}\right|\left[\mathrm{V}_{\mathrm{Pb}}^{\prime}\right]=$

$=\mathrm{p}+\left|\mathrm{q}_{\mathrm{V}_{\mathrm{Te}}} \cdot\left[\mathrm{V}_{\mathrm{Te}}^{\cdot \bullet}\right]+\right| \mathrm{q}_{\mathrm{Bi}_{\mathrm{Pb}}} \cdot\left[\mathrm{Bi}_{\mathrm{Pb}}^{\cdot}\right]$,

де $\mathrm{p}=\mathrm{A} \beta(2-2 \gamma-\delta)(1-\mathrm{x})$,

$\left[\mathrm{V}_{\mathrm{Pb}}^{\prime \prime}\right]=\mathrm{A}\left(\beta(1-\delta)(1-\mathrm{x})+\frac{1}{3} \mathrm{x}\right),\left[\mathrm{V}_{\mathrm{Pb}}^{\prime}\right]=\mathrm{A} \beta \delta(1-\mathrm{x})$,

$\left[\mathrm{Bi}_{\mathrm{Pb}}^{\bullet}\right]=\frac{2}{3} \mathrm{Ax},\left[\mathrm{V}_{\mathrm{Te}}^{\bullet \cdot}\right]=\mathrm{A} \beta \gamma(1-\mathrm{x}),\left|\mathrm{q}_{\mathrm{V}_{\mathrm{Pb}}^{\prime}}^{\prime}\right|=\left|\mathrm{q}_{\mathrm{Bi}_{\mathrm{Pb}}^{\bullet}}\right|=1$, $\left|\mathrm{q}_{\mathrm{V}_{\mathrm{Pb}}}^{\prime \prime}\right|=\left|\mathrm{q}_{\mathrm{V}_{\mathrm{Te}}^{* *}}\right|=2$.

Концентрація визначатиметься, міжвузлового згідно

телуру $\left[\mathrm{Te}_{\mathrm{i}}^{0}\right]=\mathrm{A} \beta \gamma(1-\mathrm{x})$.
Холлівська концентрація в цьому випадку:

$\mathrm{n}_{\mathrm{H}}=\mathrm{A} \beta(2-2 \gamma-\delta)(1-\mathrm{x})$

Для механізму II у випадку n-PbTe- $\mathrm{Bi}_{2} \mathrm{Te}_{3}$, згідно $з$ (5):

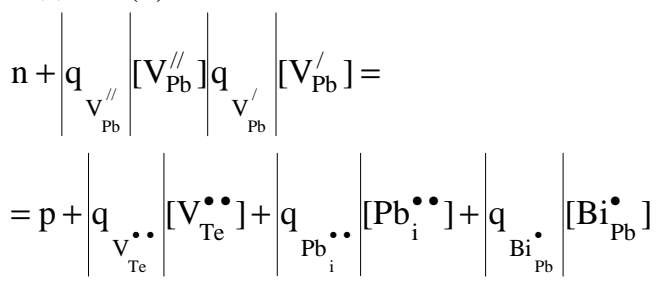

де $\mathrm{n}=\mathrm{A}((2 \alpha+\alpha \sigma \delta)(1-\mathrm{x})+\mathrm{x})$

$\left[\mathrm{V}_{\mathrm{Pb}}^{\prime \prime}\right]=\mathrm{A} \alpha \sigma(1-\sigma)(1-\mathrm{x}),\left[\mathrm{V}_{\mathrm{Pb}}^{\prime}\right]=\mathrm{A} \alpha \sigma \delta(1-\mathrm{x})$,

$\left[\mathrm{Bi}_{\mathrm{Pb}}^{\bullet}\right]=\mathrm{Ax},\left[\mathrm{V}_{\mathrm{Te}}^{\bullet \bullet}\right]=\mathrm{A} \alpha(1-\mathrm{x})$,

$\left[\mathrm{Pb}_{\mathrm{i}}^{\bullet}\right]=\operatorname{A} \alpha \sigma(1-\mathrm{x}),\left|\mathrm{q}_{\mathrm{Pb}}^{\prime}\right|=\left|{\underset{\mathrm{Bi}}{\mathrm{Pb}}}^{\mathrm{q}^{\bullet}}\right|=1$,

$\left|\mathrm{q}_{\mathrm{Pb}}^{\prime \prime}\right|=\left|\mathrm{v}_{\mathrm{Te}}^{\mathrm{q}_{\mathrm{Te}}^{. .}}\right|=\mid \mathrm{Pb}_{3} .$.

Концентрація міжвузлового телуру, згідно з (5), буде $\left[\mathrm{Te}_{\mathrm{i}}^{0}\right]=\frac{1}{2} \mathrm{Ax}$.

Холлівська концентрація носіїв струму $\mathrm{n}_{\mathrm{H}}$ в цьому випадку матиме вигляд:

$\mathrm{n}_{\mathrm{H}}=\mathrm{A}((2 \alpha+\alpha \sigma \delta)(1-\mathrm{x})+\mathrm{x})$,

Аналогічно для p-PbTe-Bi $\mathrm{Te}_{3}$ (механізм II), згідно з (6), рівняння електронейтральності:

$\left.\left|q_{\mathrm{V}_{\mathrm{Pb}}^{\prime \prime}}\right|\left[\mathrm{V}_{\mathrm{Pb}}^{\prime \prime}\right]\right]_{\mathrm{V}_{\mathrm{Pb}}^{\prime}}\left|\left[\mathrm{V}_{\mathrm{Pb}}^{\prime}\right]=\mathrm{p}+\right| \mathrm{q}_{\mathrm{V}_{\mathrm{Te}}} . .\left[\mathrm{V}_{\mathrm{Te}}^{\bullet \bullet}\right]+\left|\mathrm{q}_{\mathrm{Bi}_{\mathrm{Pb}}}\right|\left[\mathrm{Bi}_{\mathrm{Pb}}^{\bullet}\right],(13$

де $\mathrm{p}=\mathrm{A} \beta(2-2 \gamma-\delta)(1-\mathrm{x}), \mathrm{n}=\mathrm{Ax}$,

$\left[\mathrm{V}_{\mathrm{Pb}}^{\prime \prime}\right]=\mathrm{A} \beta(1-\delta)(1-\mathrm{x}),\left[\mathrm{V}_{\mathrm{Pb}}^{\prime}\right]=\mathrm{A} \beta \delta(1-\mathrm{x})$,

$\left[\mathrm{Bi}_{\mathrm{Pb}}^{\bullet}\right]=\mathrm{Ax},\left[\mathrm{V}_{\mathrm{Te}}^{\bullet \bullet}\right]=\mathrm{A} \beta \gamma(1-\mathrm{x})$,

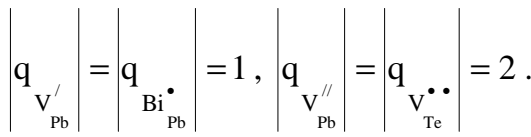

Згідно з (6), концентрація міжвузлового телуру запишеться у вигляді $\left[\mathrm{Te}_{\mathrm{i}}^{0}\right]=\mathrm{A}\left(\beta \gamma(1-\mathrm{x})+\frac{1}{2} \mathrm{x}\right)$.

Холлівська концентрація в цьому випадку:

$\mathrm{n}_{\mathrm{H}}=\mathrm{A}|\beta(2-2 \gamma-\delta)(1-\mathrm{x})-\mathrm{x}|$

\section{Аналіз результатів дослідження}

Деякі результати проведених розрахунків холлівської концентрації носіїв струму i концентрації домінуючих точкових дефектів, згідно $з$ формулами (7)-(14), представлено на Рис. 3-5. 
У випадку реалізації механізму I (заміщення позицій плюмбуму та утворення катіонних вакансій) має місце незначне зменшення концентрації основних носіїв зі збільшенням частки $\mathrm{Bi}_{2} \mathrm{Te}_{3}$ як для n-PbTe- $\mathrm{Bi}_{2} \mathrm{Te}_{3}$ (Рис. 3, a - крива 1), так i для p-PbTe-Bi ${ }_{2} \mathrm{Te}_{3}$ (Рис. 3,б - крива 1). При реалізації механізму II (заміщення позицій плюмбуму i утворення міжвузлового телуру) у n-PbTe- $\mathrm{Bi}_{2} \mathrm{Te}_{3}$ холлівська концентрація носіїв струму помітно зростає зі збільшенням вмісту домішки (Рис. 4, а - крива 1). У випадку p-PbTe-Bi $\mathrm{Te}_{3}$ (Рис. 4,6 - крива 1) зі збільшенням частки $\mathrm{Bi}_{2} \mathrm{Te}_{3}$ має місце зменшення концентрації основних носіїв струму, конверсія провідності 3 p- на n-тип при малому вмісті домішки i подальше збільшення концентрації електронів.

Особливості, що спостерігаються у зміні концентрації носіїв заряду, пов'язані 3 характерними співвідношеннями між окремими точковими дефектами (Рис. 3-4). Так, для механізму I у кристалах n-PbTe-Bi $\mathrm{Te}_{3}$ (Рис. 3,a) найбільший внесок у провідність дають іонізовані атоми бісмуту на місці плюмбуму $\mathrm{Bi}_{\mathrm{Pb}}^{+}$ (Рис. 3, а - крива 2), двозарядні катіонні вакансії $\mathrm{V}_{\mathrm{Pb}}^{2-} \quad$ (Рис. 3, a - крива 3), концентрація яких помітно зростає зі збільшенням вмісту домішки та двозарядні аніонні вакансії $\mathrm{V}_{\mathrm{Te}}^{2+}$ (Рис. 3, а крива 5), концентрація яких зі зміною складу твердого розчину змінюється незначно. Концентрації ж однозарядних катіонних вакансій $\mathrm{V}_{\mathrm{Pb}}^{-}$та міжвузлового плюмбуму $\mathrm{Pb}_{\mathrm{i}}^{2+}$ значно менші (Рис. 3, а - криві 4, 6). Для кристалів р-

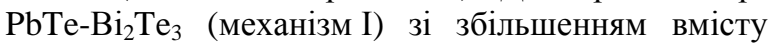
$\mathrm{Bi}_{2} \mathrm{Te}_{3}$ спостерігається значне зростання концентрації іонізованого бісмуту в позиціях плюмбуму $\mathrm{Bi}_{\mathrm{Pb}}^{+}$(Рис. 3,6 - крива 2) та двозарядних катіонних вакансій $\mathrm{V}_{\mathrm{Pb}}^{2-}$ (Рис. 3,б крива 3). При цьому концентрації $\mathrm{V}_{\mathrm{Pb}}^{-}, \mathrm{V}_{\mathrm{Te}}^{2+}, \mathrm{Te}_{\mathrm{i}}^{0}$ практично не змінюються (Рис. 3, б -криві 4, 5, 7).

3 Рис. 4 видно, що для механізму II у кристалах n-PbTe- $\mathrm{Bi}_{2} \mathrm{Te}_{3}$ найбільший внесок у провідність дають домішкові дефекти $\mathrm{Bi}_{\mathrm{Pb}}^{+}$ (Рис. 4, а - крива 2), а також аніонні вакансії $\mathrm{V}_{\mathrm{Te}}^{2+}$ (Рис. 4,a - крива 5). При цьому, якщо концентрація перших різко зростає, то других змінюється незначно зі збільшенням вмісту $\mathrm{Bi}_{2} \mathrm{Te}_{3}$ у твердому розчині. Концентрація інших дефектів $\mathrm{V}_{\mathrm{Pb}}^{2-}, \quad \mathrm{V}_{\mathrm{Pb}}^{-}, \mathrm{Pb}_{\mathrm{i}}^{2+} є$ значно меншою (Рис. 4, а криві $3,4,6)$. Міжвузловий телур $\mathrm{Te}_{\mathrm{i}}^{0}$ має значну концентрацію, яка зростає зі збільшенням вмісту $\mathrm{Bi}_{2} \mathrm{Te}_{3}$ (Рис. 4,a - крива 7). У випадку p-PbTe$\mathrm{Bi}_{2} \mathrm{Te}_{3}$ для механізму II (Рис. 4,б) домінуючими дефектами $€ \mathrm{Bi}_{\mathrm{Pb}}^{+}, \mathrm{Te}_{\mathrm{i}}^{0}, \mathrm{~V}_{\mathrm{Pb}}^{2-}$. При цьому якщо концентрації $\left[\mathrm{Bi}_{\mathrm{Pb}}^{+}\right]$i $\left[\mathrm{Te}_{3}^{0}\right]$ збільшуються зі збільшенням вмісту домішки (Рис. 4,б - криві 2, 7), то $\left[\mathrm{V}_{\mathrm{Pb}}^{2-}\right]$ зменшується незначно (Рис. 4,б крива 3). Точкові дефекти $\mathrm{V}_{\mathrm{Pb}}^{-} \mathrm{i} \mathrm{V}_{\mathrm{Te}}^{2+}$ суттєво не впливають на провідність, i їх концентрація не змінюється зі збільшенням вмісту $\mathrm{Bi}_{2} \mathrm{Te}_{3}$ (Рис. 4, б - криві 4, 5).

Порівнюючи отримані результати розрахунків 3 експериментом (Рис. 1 - крива 2; Рис. 2 крива 2) щодо активної донорної дії $\mathrm{Bi}_{2} \mathrm{Te}_{3}$, можна зробити висновок про те, що реалізується механізм II. При цьому збільшення початкового відхилення від стехіометрії зі сторони телуру ( $\beta$ ) для випадку p-PbTe-Bi $\mathrm{Te}_{3}$ (механізм II) призводить до зміщення точки термодинамічного p-n-переходу в сторону більшого вмісту $\mathrm{Bi}_{2} \mathrm{Te}_{3}$ (x). Залежність холлівської концентрації від початкового відхилення від стехіометрії в основній матриці і вмісту домішки як в n-PbTe$\mathrm{Bi}_{2} \mathrm{Te}_{3}$, так i p-PbTe-Bi $\mathrm{Te}_{3}$ добре ілюструють просторові діаграми $\mathrm{n}_{\mathrm{H}^{-}} \alpha(\beta)$-х (Рис. 5).

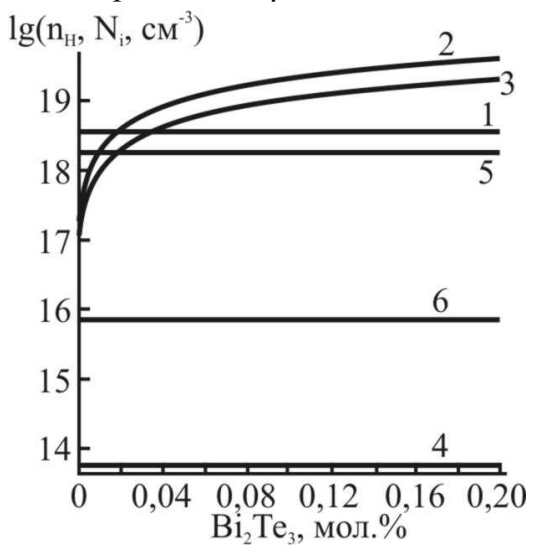

a)

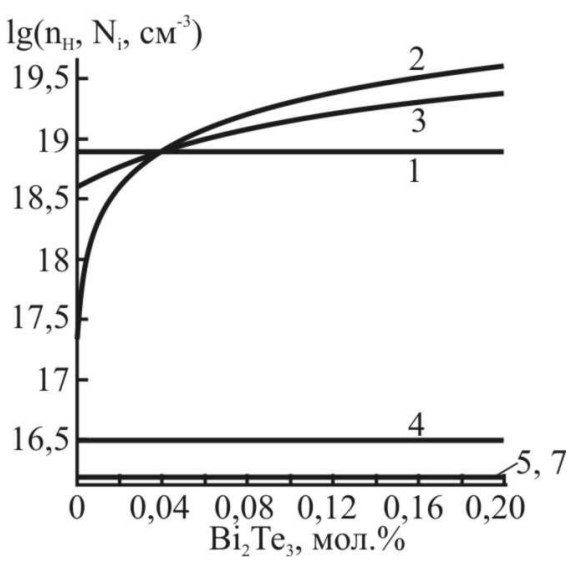

б)

Рис. 3. Залежність холлівської концентрації носіїв струму $\left(1-\mathrm{n}_{\mathrm{H}}\right)$ та концентрації домінуючих точкових дефектів (2-7 - $\left.\mathrm{N}_{\mathrm{i}}\right)$ кристалів n-PbTe$\mathrm{Bi}_{2} \mathrm{Te}_{3}(\alpha=0,006$ aт. $\%, \delta=0,8 \%, \sigma=0,4 \%)$ (a) та p-PbTe-Bi ${ }_{2} \mathrm{Te}_{3} \quad(\beta=0,013$ ат. $\%$, $\delta=0,8 \%, \gamma=0,4 \%$ ) (б) від вмісту $\mathrm{Bi}_{2} \mathrm{Te}_{3}$. Механізм I. $2-\mathrm{Bi}_{\mathrm{Pb}}^{+} ; 3-\mathrm{V}_{\mathrm{Pb}}^{2-} ; 4-\mathrm{V}_{\mathrm{Pb}}^{-}$; $5-\mathrm{V}_{\mathrm{Te}}^{2+} ; 6-\mathrm{Pb}_{\mathrm{i}}^{2+} ; 7-\mathrm{Te}_{\mathrm{i}}^{0}$. 


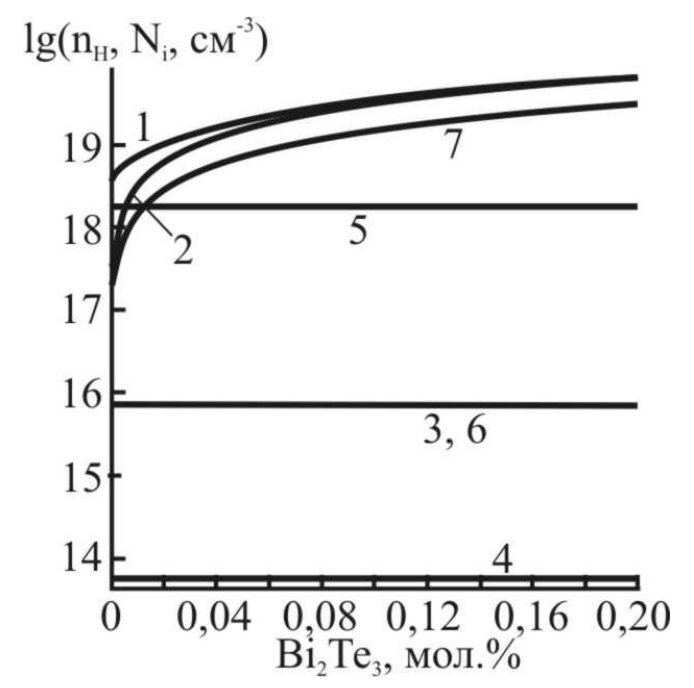

a)

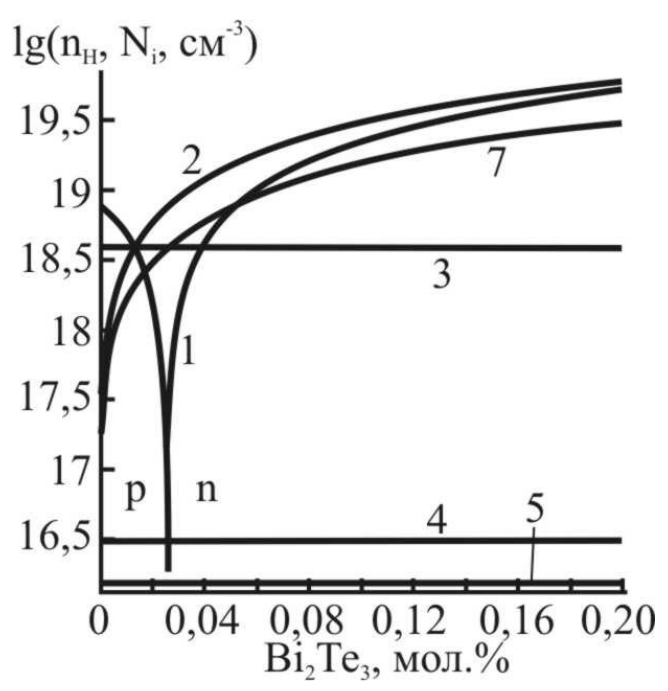

б)

Рис. 4. Залежність холлівської концентрації носіїв струму $\left(1-\mathrm{n}_{\mathrm{H}}\right)$ та концентрації домінуючих точкових дефектів (2-7 - $\left.\mathrm{N}_{\mathrm{i}}\right)$ кристалів n-PbTe-Bi $\mathrm{Te}_{3} \quad(\alpha=0,006$ ат. $\%$, $\delta=0,8 \%, \sigma=0,4 \%$ ) (a) та p-PbTe-Bi $\mathrm{Te}_{3}$ (б) від вмісту $\mathrm{Bi}_{2} \mathrm{Te}_{3}$. Механізм II. $2-\mathrm{Bi}_{\mathrm{Pb}}^{+}$; $3-\mathrm{V}_{\mathrm{Pb}}^{2-} ; 4-\mathrm{V}_{\mathrm{Pb}}^{-} ; 5-\mathrm{V}_{\mathrm{Te}}^{2+} ; 6-\mathrm{Pb}_{\mathrm{i}}^{2+} ; 7-\mathrm{Te}_{\mathrm{i}}^{0}$ $(\beta=0,013$ aт. $\%, \delta=0,8 \%, \gamma=0,4 \%)$.

\section{Висновки}

1. Проаналізована залежність термоелектричних параметрів твердих розчинів n-PbTe- $\mathrm{Bi}_{2} \mathrm{Te}_{3}$ i $\mathrm{p}-\mathrm{PbTe}-\mathrm{Bi}_{2} \mathrm{Te}_{3}$ від складу i температури та запропоновано кристалохімічні механізми їхньго утворення.

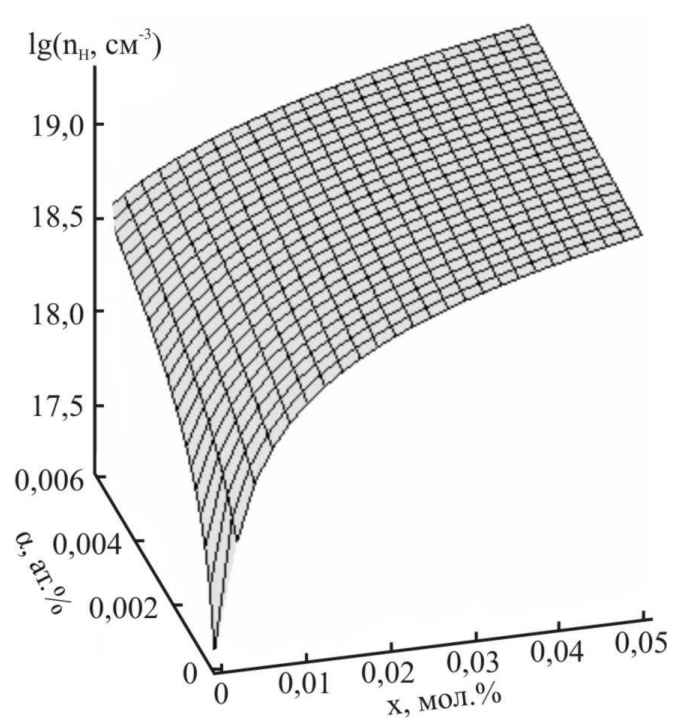

a)

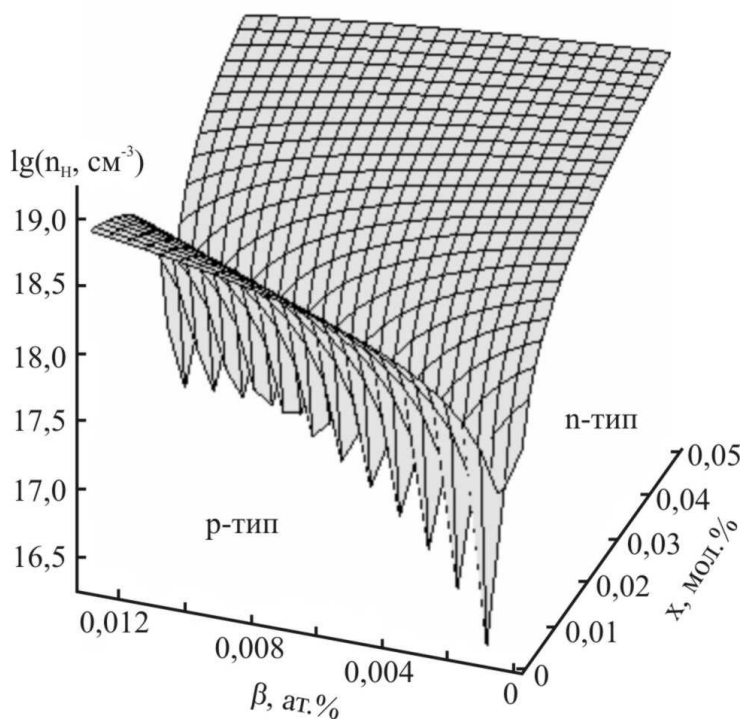

б)

Рис. 5 Просторові діаграми залежності холлівської концентрації носіїв струму $\left(\mathrm{n}_{\mathrm{H}}\right)$ від початкового відхилення від стехіометрії в основній матриці $(\alpha-(\mathrm{a}), \beta$ - (б)) та вмісту $\mathrm{Bi}_{2} \mathrm{Te}_{3}(\mathrm{x})$ у твердих розчинах $\mathrm{n}-\mathrm{PbTe}-\mathrm{Bi}_{2} \mathrm{Te}_{3}$ $(\delta=0,8 \%, \sigma=0,4 \%)$ (a) та $\mathrm{p}-\mathrm{PbTe}_{-} \mathrm{Bi}_{2} \mathrm{Te}_{3}$ $(\delta=0,8 \%, \gamma=0,4 \%)(б)$. Механізм II.

2. На основі розроблених кристалоквазіхімічних формул розраховано залежності холлівської концентрації носіїв струму і концентрації окремих точкових дефектів твердих розчинів від складу та початкового відхилення від стехіометрії в основній матриці n-PbTe i p-PbTe.

3. Встановлено, що домінуючим механізмом утворення твердого розчину $\mathrm{PbTe}^{-\mathrm{Bi}_{2} \mathrm{Te}_{3}} \epsilon$ заміщення бісмутом позицій плюмбуму $\mathrm{Bi}_{\mathrm{Pb}}^{+} 3$ утворенням міжвузлового телуру $\mathrm{Te}_{\mathrm{i}}^{0}$. 
Робота виконана згідно з науковими проектами Державного агентства з питань науки, інновацій та інформації Украӥни (державний реєстраційний номер 0110U007675) та МОН Украӥни (державний реєстраиійний номер 0107U006768).

\section{Літературні посилання}

[1]. Л.И. Анатычук, Термоэлементы термоэлектрические устройства: Справочник, Наукова думка, Київ, 1979, 676 с.

[2]. P. Zhu, Y. Imal, Y. Isoda, Y. Shinohara, X. Jia, G. Zou, J. Phys.: Condens. Matter 17 (2005) 7319-7326.

[3]. В.М. Шперун, Д.М. Фреїк, Р.І. Запухляк, Термоелектрика плюмбум телуриду та його аналогів, Плай, Івано-Франківськ, 2000, 250 с.

[4]. Е.А. Гурлева, П.П. Константинов, Л.В. Прокофьева, Ю.Н. Равич, М.Н. Федоров, Физ. тех. полупроводн. 37 (2003) 292-298.

[5]. T.V. Tavrina, E.I. Rogacheva, V.I. Pinegin, Mold. J. Phys. Sci. 4 (2005) 430-434.

[6]. Б.А. Ефимова, Г.Ф. Захарюгина, Л.А. Коломоец, Изв. АН СССР. Неорг. матер. 4 (1968) 32-38.
[7]. Е.И. Рогачева, С.А. Лаптев, В.С. Плоская, В.А. Ефимова, Изв. АН СССР. Неорг. матер. 20 (1984) 1350-1353.

[8]. Н.С. Голованова,

В.П. Зломанов, О.И. Тананаева, Л.Д. Личева, Изв. АН СССР. Неорг. матер. 20 (1984) 574-577.

[9]. T.A. Christakudi, G.Ch. Christakudis, L.D. Borissova, Phys. Status Solidi B 190 (1995) 537-544.

[10]. Л.Е. Шелимова, О.Г. Карпинский, П.П. Константинов, Е.С. Авилов, М.А. Кретова, И.Ю. Нихезина, В.С. Земсков, Перcn. Mamep. 5 (2009) 5-13.

[11]. P. Zhu, Y. Imai, Y. Isoda, Y. Shinohara, X. Jia, G. Zou, J. Alloys Compd. 420 (2006) 233-236.

[12]. F.J. DiSalvo, Science 285 (1999) 703-706.

[13]. K. Kishimoto, K. Yamamoto, T. Koyanagi, Jpn. J. Appl. Phys. 42 (2003) 501-508.

[14]. О.С. Водорез, А.А. Месечко, Н.В. Щуркова, Е.И. Рогачева, Нові технол. 2 (2010) 84-89.

[15]. С.С. Лисняк, Неорг. матер. 29 (1992) 1913-1917.

[16]. В.М. Бойчук, О.В. Ткачик, Л.В. Туровська, Н.І. Дикун, Фіз. хім. тв. тіла 8 (2007) 366-373. 